\title{
Ratiometric fluorescent probe for enantioselective detection of $D$-cysteine in aqueous solution
}

\author{
Xiao-bo Zhou, Wing-Hong Chan", Albert W. M. Lee and Chi-Chung Yeung
}

\section{Full Research Paper}

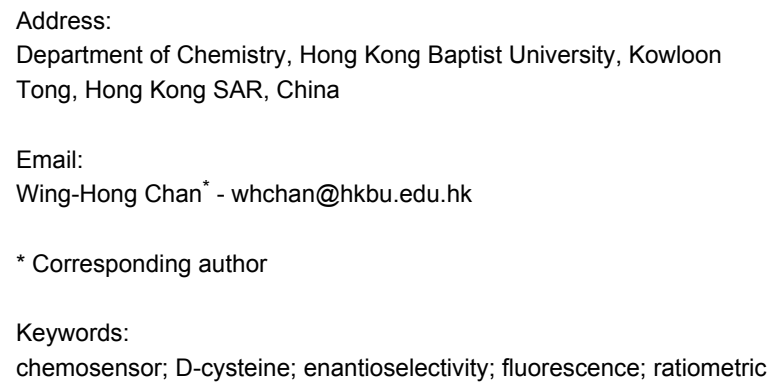

\author{
Beilstein J. Org. Chem. 2011, 7, 1508-1515. \\ doi:10.3762/bjoc.7.176 \\ Received: 08 August 2011 \\ Accepted: 20 October 2011 \\ Published: 09 November 2011 \\ Associate Editor: N. Sewald \\ () 2011 Zhou et al; licensee Beilstein-Institut. \\ License and terms: see end of document.
}

\begin{abstract}
A ratiometric fluorescent probe based on a $\mathrm{Cd}^{2+}-\mathbf{A C A Q}$ complex was designed and demonstrated for the chemo- and enantioselective detection of cysteine in 99:1 buffered HEPES:ACN solutions. Under the measuring conditions, the sensor demonstrates high selectivity toward Cys against Hcy and GSH, and an enantioselectivity of 3.35 can be achieved for antipodal forms of Cys.
\end{abstract}

\section{Introduction}

The rapid, sensitive, and selective sensing of biologically relevant thiols including cysteine (Cys), homocysteine (Hcy) and glutathione (GSH) has attracted significant interest in the sensor community (Figure 1) [1]. All three of these thiols are present in living cells at different concentration levels and play vital roles in controlling redox-related biological processes [2]. Abnormal levels of Cys and Hcy are associated with a variety of human diseases [3-5]. Hence, the development of efficient and selective methods capable of quantifying biological thiols under physiological conditions is of interest in a wide variety of disciplines including chemistry and medicine. Owing to the intrinsic sensitivity of fluorescence, the development of fluorescent probes for thiols has been extensively invesigated. The subject has been recently reviewed by Yoon and coworkers [6]. A<smiles>N[C@@H](CS)C(=O)O</smiles><smiles>NC(CS)C(=O)O</smiles>

L-Cys<smiles>N[C@@H](CCS)C(=O)O</smiles>

D-Hcy<smiles>N[C@@H](CCS)C(=O)O</smiles>

L-Hcy

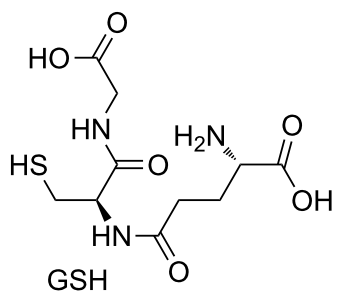

Figure 1: Structures of biological active thiols. 
number of novel sensing strategies have been designed that mostly relied on the high nucleophilicity of the sulfhydryl group. For instance, Michael addition of thiols onto fluorescent "acceptors" can trigger a change in the fluorescence outputs of the sensory materials [7-11]. The facile cyclization of $\beta$ - or $\gamma$-aminothiols with aldehydes containing fluorescent probes forms the basis for the development of several fluorescent probes [12-17]. In addition, cleavage of disulfide-based probes by thiols [18-21] and other thiol-sensing tactics have been documented [22-28]. As an improved sensing device, a ratiometric fluorescence probe monitors the emission intensities at two different wavelengths, which should provide a built-in correction for instrumental defects and photodegradation of sensing materials. In this context, a few ratiometric fluorescent chemosensors for the detection of thiols have been constructed [29-31]. Recently, on the basis of a native chemical-ligation reaction, Lin and coworkers reported a FRET-based probe suitable for ratiometric imaging of cysteine in living cells [31]. Therefore, it is a challenging task to design probes for the detection of Cys. In addition, to our knowledge, an enantioselective fluorescent chemosensor for D-Cys has not been reported in the literature. It is well known that D-Cys is a powerful inhibitor of E. coli, some strains of which can have very serious effects on human health [32].

On the basis of multipoint electrostatic interactions and structure complementarity of the host-guest, we have rationally designed and synthesised a bis(spiropyran) as a fluorescence turn-on probe for selective binding of GSH [33]. We have also developed the first spiropyran-metal sensing ensemble for selective detection of Cys and Hcy [34]. Continuing our interests in the design and the synthesis of fluorescent chemosensors for biologically active molecules, we describe herein a ratiometric fluorescent probe that can be exploited for the enantioselective recognition of cysteine in aqueous solutions. Interestingly, the probe is only slightly responsive to Hcy and GSH.

\section{Results and Discussion}

N-Alkylation of trans-1,2-diaminocyclohexane with a pair of 9-carboxamidoquinoline moieties through methylene linkers afforded multifunctionalized ACAQ (Figure 2). Bearing six metal ligating sites, ACAQ was developed by us as a cellpermeable, fluorescent, ratiometric sensing probe for the detection of $\mathrm{Zn}^{2+}$ and $\mathrm{Cd}^{2+}$ [35].<smiles>O=C(CN[C@H]1CCCC[C@@H]1NCC(=O)Nc1cccc2cccnc12)Nc1cccc2cccnc12</smiles>

Figure 2: The structure of ACAQ.

Operating according to the intramolecular charge-transfer (ICT) mechanism, complexation of ACAQ with either $\mathrm{Cd}^{2+}$ or $\mathrm{Zn}^{2+}$ triggers a ratiometric change in the emission band of ACAQ. A redshift of the emission band of ACAQ from $400 \mathrm{~nm}$ to $500 \mathrm{~nm}$ was observed as a result of the metal-host interaction. Adding a quantity of cysteine of up to $25 \mu \mathrm{M}$ into a $2: 8$ aqueous acetonitrile buffered solution (HEPES, pH 7.40) of the $\mathrm{Zn}^{2+}-\mathbf{A C A Q}$ complex did not induce any change in its fluorescence (Figure 3a). Conceivably, the relatively weak interaction
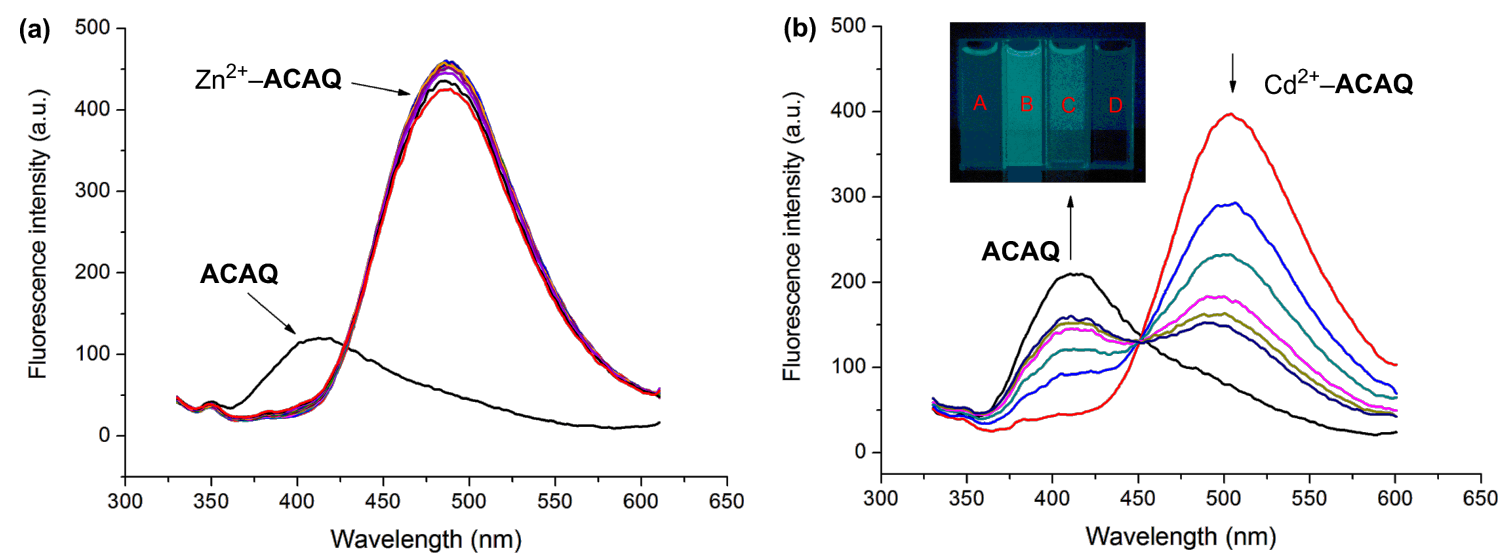

Figure 3: Emission spectra of (a) $\mathrm{Zn}^{2+}-\mathbf{A C A Q}$ or (b) $\mathrm{Cd}^{2+}-\mathbf{A C A Q}$ complex $(5 \mu \mathrm{M})$ at increasing concentrations of Cys $(0,1.0,2.0,3.0,4.0,5.0$ equiv) in buffered solution (10 mM, HEPES, $80 \%$ ACN, pH 7.4) at $298 \mathrm{~K}$. Excitation wavelength was $315 \mathrm{~nm}$. Inset in (b): Visible emission (irradiated by $365 \mathrm{~nm}$ light) observed. A: Only ACAQ; B: $\mathrm{Cd}^{2+}-\mathbf{A C A Q}$; C: $\mathrm{Cd}^{2+}-\mathbf{A C A Q} / 0.5$ equiv Cys; D: $\mathrm{Cd}^{2+}-\mathbf{A C A Q} / 2.0$ equiv Cys. 
between zinc and cysteine did not perturb the structure of the $\mathrm{Zn}^{2+}$-ACAQ complex, as was evident by the intact nature of its fluorescence spectrum. On the other hand, progressive addition of cysteine to the buffered solution of the corresponding cadmium complex $\left(\mathrm{Cd}^{2+}-\mathbf{A C A Q}\right)$ can induce a distinctive ratiometric fluorescence change characterized by the formation of an obvious isoemissive point at $450 \mathrm{~nm}$ (Figure $3 \mathrm{~b}$ ). We envisioned that the strong binding affinity of cysteine to $\mathrm{Cd}^{2+}$ perturbs its interaction with ACAQ in such a way that the ICT process within the complex is greatly retarded. When 5 equivalents of Cys is introduced into the probe solution, the emission spectrum of the resultant solution is very similar to that of the original spectrum of pure ACAQ.

To define the optimium operative conditions of the sensing probe for detecting cysteine, different aqueous solvent systems were chosen for subsequent investigations. On the basis of the results of the fluorescence titrations, the respective binding constants under different measuring conditions were estimated from the nonlinear fits (Table 1). In 20\% aqueous buffer solutions, acetonitrile (ACN) emerged as the best cosolvent, among other polar solvents, to favor the formation of the most stable complex between the probe and Cys, as characterized by the highest association constant. When a higher content of water was used, the association constant of $\mathrm{Cd}^{2+}-\mathbf{A C A Q}$ and L-cysteine decreased.

\begin{tabular}{|c|c|c|}
\hline solvent system ${ }^{a}$ & $\mathrm{~K}_{\text {ass }}\left(\mathrm{M}^{-1}\right)$ & $R^{2}$ \\
\hline DMSO:HEPES = 8:2 & $(6.42 \pm 1.56) \times 10^{4}$ & 0.9962 \\
\hline MeOH:HEPES = 8:2 & $(0.39 \pm 0.24) \times 10^{4}$ & 0.9715 \\
\hline EtOH:HEPES = 8:2 & $(2.50 \pm 0.68) \times 10^{4}$ & 0.9860 \\
\hline ACN:HEPES = 8:2 & $(1.20 \pm 0.30) \times 10^{5}$ & 0.9790 \\
\hline ACN $:$ HEPES $=5: 5$ & $(0.42 \pm 0.12) \times 10^{4}$ & 0.9923 \\
\hline ACN:HEPES $=2: 8$ & $(0.66 \pm 0.03) \times 10^{4}$ & 0.9977 \\
\hline
\end{tabular}

aHEPES in $10 \mathrm{mM}$ at $\mathrm{pH} 7.4$.
It is noteworthy that irrespective of the exact solvent composition of the aqueous solutions the binding affinity of the probe to Cys is fairly strong, as evidenced by the binding constants. On the other hand, the Job's plot confirms the 1:1 binding stoichiometry of the sensing ensemble and Cys (Figure 4).

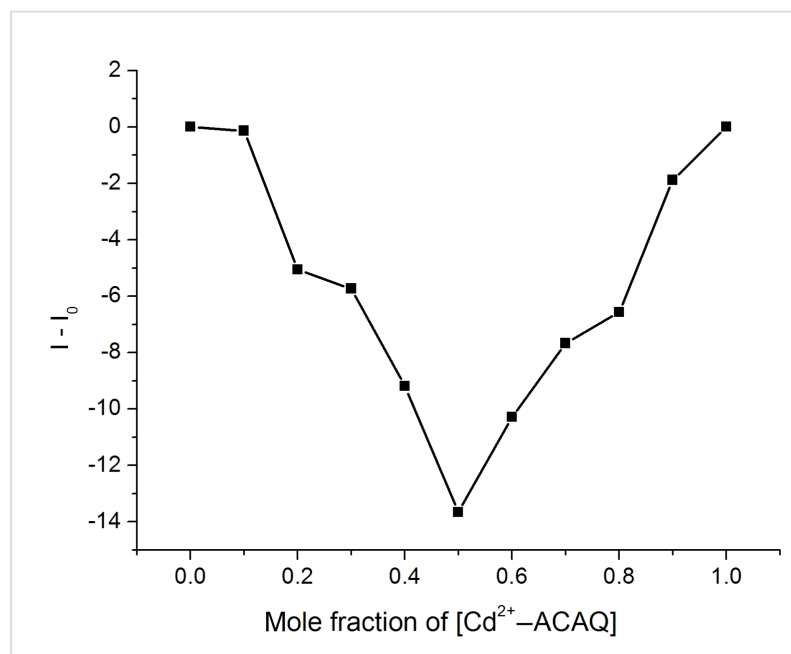

Figure 4: Job's plot of $\mathrm{Cd}^{2+}-\mathrm{ACAQ}$ in $10 \mathrm{mM}$ HEPES buffer $(\mathrm{pH} 7.4)$ at $298 \mathrm{~K}$. The sum of the concentrations of the host and D-Cys is $5 \mu \mathrm{M}$ (emission at $500 \mathrm{~nm}$ ).

To explore the chiral recognition ability of the sensory ensemble, a comparative study of the binding of the sensor to antipodal forms of Cys in different media was undertaken. On the basis of fluorescence titration results, as shown in Table 2, the sensory probe displays a modest enantioselectivity of 3.35 conferred by the chiral trans-1,2-diaminocyclohexane moiety for recognizing D-cysteine in 1\% ACN/HEPES buffered solutions (pH 7.4) (Figure 5). Apparently, owing to the structure complementarity of the host-guest, D-cysteine outperforms its enantiomer in forming a more stable complex with $\mathrm{Cd}^{2+}-\mathbf{A C A Q}$.

As cadmium is well-known for its strong affinity to sulfurcontaining compounds, we envisioned that the $\mathrm{Cd}^{2+}$-bound

Table 2: Association constants $\mathrm{K}_{\mathrm{ass}}\left(\mathrm{M}^{-1}\right)$ of $\mathrm{Cd}^{2+}-\mathrm{ACAQ}^{\mathrm{a}}$ with antipodal Cys in different solvents

\begin{tabular}{|c|c|c|c|}
\hline ACN:HEPES ${ }^{b}$ & guest & $\mathrm{K}_{\text {ass }}\left(\mathrm{M}^{-1}\right)$ & enantioselectivity \\
\hline \multirow{2}{*}{$8: 2$} & D-Cys & $(2.07 \pm 0.37) \times 10^{5}$ & \multirow{2}{*}{$\mathrm{K}_{\mathrm{D}} / \mathrm{K}_{\mathrm{L}}=1.73$} \\
\hline & L-Cys & $(1.20 \pm 0.30) \times 10^{5}$ & \\
\hline \multirow{2}{*}{$5: 5$} & D-Cys & $(1.54 \pm 0.09) \times 10^{4}$ & \multirow{2}{*}{$\mathrm{K}_{\mathrm{D}} / \mathrm{K}_{\mathrm{L}}=3.67$} \\
\hline & L-Cys & $(0.42 \pm 0.12) \times 10^{4}$ & \\
\hline \multirow{2}{*}{$1: 99^{c}$} & D-Cys & $(2.78 \pm 0.36) \times 10^{4}$ & \multirow{2}{*}{$\mathrm{K}_{\mathrm{D}} / \mathrm{K}_{\mathrm{L}}=3.35$} \\
\hline & L-Cys & $(0.83 \pm 0.07) \times 10^{4}$ & \\
\hline
\end{tabular}

a In $5 \mu \mathrm{M}$; ${ }^{\mathrm{b}} \mathrm{HEPES}$ in $10 \mathrm{mM}$ at $\mathrm{pH} 7.4$; ${ }^{\text {in }} 10 \mu \mathrm{M}$. 

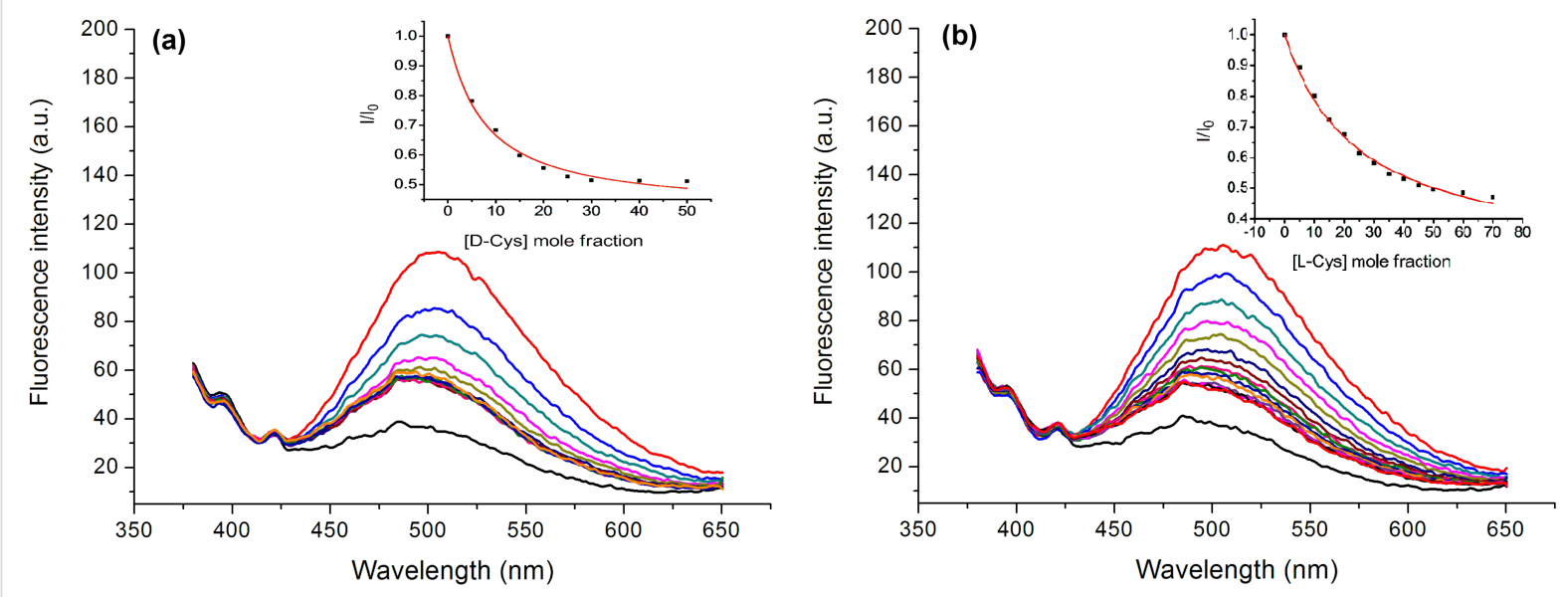

Figure 5: Fluorescence spectra of $\mathrm{Cd}^{2+}-\mathrm{ACAQ}(10 \mu \mathrm{m})$ upon the titration of (a) D-Cys and (b) L-Cys in buffer solution (10 $\mu \mathrm{M}, \mathrm{HEPES}, 1 \% \mathrm{ACN}$, $\mathrm{pH} 7.4$ ) at $298 \mathrm{~K}$ with $\lambda_{\mathrm{ex}}=350 \mathrm{~nm}$. Inset is the titration data point and the nonlinear least-squares fitting curve at $500 \mathrm{~nm}$.

ACAQ complex would demonstrate chemoselective binding toward amino acids. Among 22 amino acids, a tripeptide, cysteine derivative and $\beta$-mercaptopropionic acid (MPA), only Cys demonstrated strong interaction with the probe (Figure 6). As evidenced by the relative fluorescence quenching ability of the thiols, it is noteworthy that only marginal bindings of the probe to glutathione (GSH) and DL-Hcy were found. The corresponding fluorescence response of each of the analytes to the probe can be found in Figure 7. In the control experiments, when 20 equivalents of the amino acids were added to ACAQ solutions under the same measuring conditions, the weak emis-

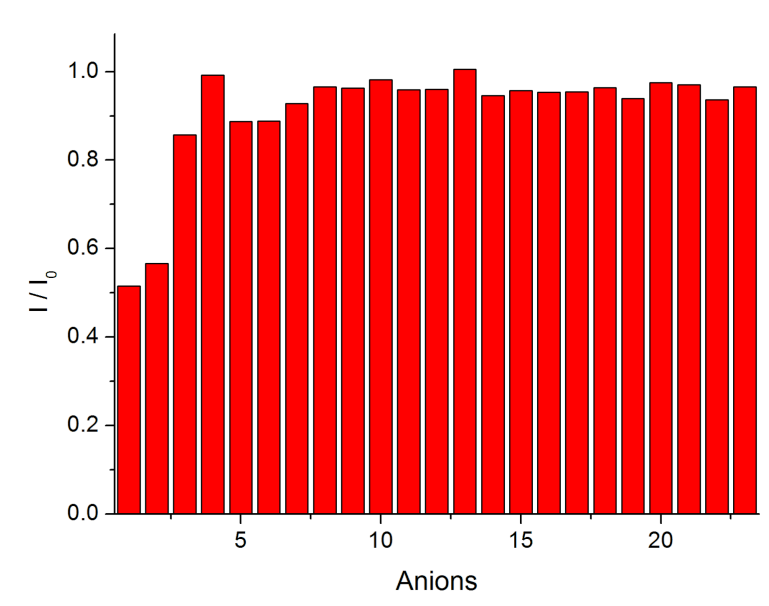

Figure 6: Fluoresence emission change of $\mathrm{Cd}^{2+}-\mathrm{ACAQ}$ at $500 \mathrm{~nm}$ in response to the addition of 15 equiv amino acids in 1:99 ACN:HEPES buffer solution (pH 7.4) at $298 \mathrm{~K}$ (excitation at $350 \mathrm{~nm})$ : 1. D-Cys; 2. L-Cys; 3. GSH; 4. L-Met; 5. DL-Hcy; 6. N-Ac-L-Cys; 7. MPA; 8. L-Asp; 9. D-Asp; 10. D-Glu; 11. L-Glu; 12. D-Lys; 13. L-Lys; 14. D-Ser; 15. L-Ser; 16. D-Tyr; 17. L-Tyr; 18. D-Val; 19. L-Val; 20. D-Phe; 21. L-Phe; 22. D-His; 23. L-His. sion peak of the native ACAQ centred at $405 \mathrm{~nm}$ experienced an intensity change of less than $5 \%$. Thus, the role of $\mathrm{Cd}^{2+}$ in the function of the sensory probe is evident and indispensible.

Furthermore, the binding interaction between the probe and the antipodal cysteines was investigated by means of UV titrations. In corroboration with the fluorescence study, a clear isosbestic point at around $330 \mathrm{~nm}$ was apparent when increasing concentrations of Cys were introduced into the buffered 1:1 ACN/ HEPES solution of $\mathrm{Cd}^{2+}-\mathbf{A C A Q}(25 \mu \mathrm{M})$. The higher concentration of the sensor compared to that used in the fluorescence

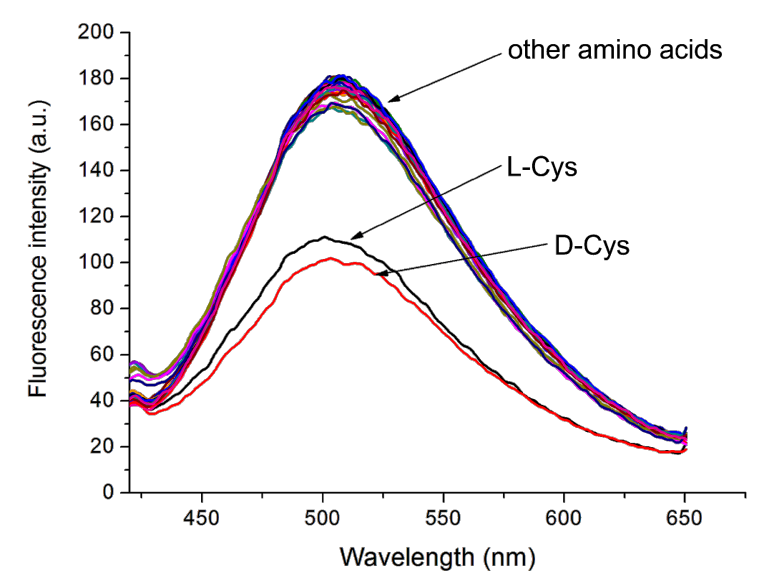

Figure 7: Fluorescence spectra of $(10 \mu \mathrm{m}) \mathrm{Cd}^{2+}-\mathrm{ACAQ}$ upon the titration of various amino acids in buffer solution (10 mM, HEPES,

$1 \% \mathrm{ACN}, \mathrm{pH} 7.4$ ) at $298 \mathrm{~K}$ (excitation at $350 \mathrm{~nm}$ ). Other amino acids include: GSH; L-Met; DL-Hcy; N-Ac-L-Cys; MPA; L-Asp; D-Asp; D-Glu; L-Glu; D-Lys; L-Lys; D-Ser; L-Ser; D-Tyr; L-Tyr; D-Val; L-Val; D-Phe; L-Phe; D-His; L-His. 

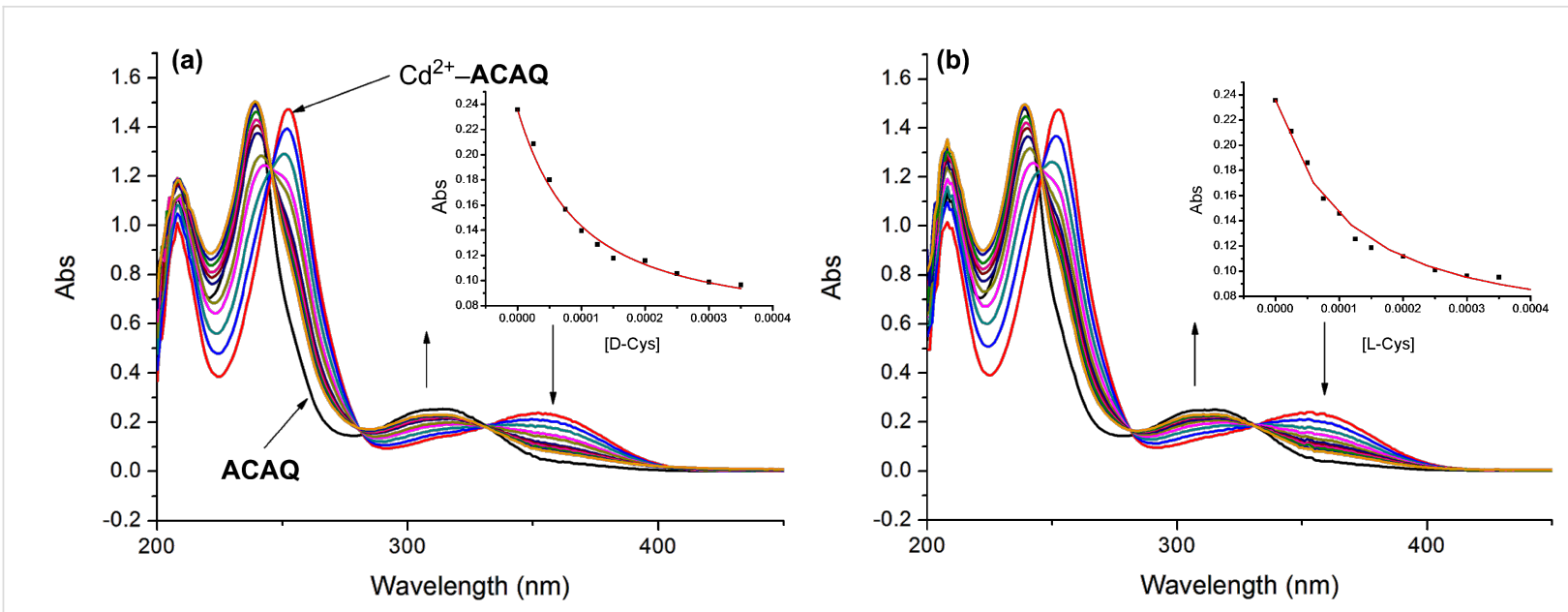

Figure 8: UV spectra of $\mathrm{Cd}^{2+}-\mathrm{ACAQ}(25 \mu \mathrm{m})$ upon the titration of (a) D-Cys, (b) L-Cys (0-12 equiv) in buffer solution (10 mM , HEPES, $50 \%$ ACN, $\mathrm{pH} 7.4$ ) at $298 \mathrm{~K}$. The inset shows the titration data points and the nonlinear least-squares fitting curve.

study led to the deterioration of its chiral recognizing ability for cysteines, to give a lower value of $1.22\left(\mathrm{~K}_{\mathrm{D}} / \mathrm{K}_{\mathrm{L}}\right)$ (Figure 8).

Considering the fact that Cys is a trifunctional amino acid, it is interesting to unravel its binding mode with the cadmiumcentred fluorescent chemosensor ACAQ. To shed light on the binding mechanism of Cys with the probe, seven other sulfurcontaining molecules were chosen as control compounds (Table 3). The extent of fluorescence quenching of the sensory ensemble at $500 \mathrm{~nm}$ triggered by the addition of 20 equivalents of each of the guest molecules was determined, and the results are shown in Table 3. Upon careful investigation of the relative quenching efficiency of the guest molecules on the sensor, it becomes apparent that the presence of free amine and thiol groups is essential for the effective interaction with the cadmium metal centre of the sensor. Interestingly, Hcy bearing a $\beta$-mercaptoamino moiety is far less effective at binding with the cadmium of the probe in comparison with the $\alpha$-mercaptoamino group present in Cys. When the thiol group in Hcy is methylated, as in methionine, its power to bind to the sensor is completely lost. As none of the bifunctional $\alpha$-amino acids caused any fluorescence quenching of the probe, the presence of $\beta$-mercaptoamino moiety in cysteine may confer a synergistic binding affinity of its carboxyl group to $\mathrm{Cd}^{2+}-\mathbf{A C A Q}$. Such a proposition was supported by the observation that by converting the carboxyl group of cysteine into its methyl ester, the

Table 3: The quenching factor of $\mathrm{Cd}^{2+}-\mathrm{ACAQ}$ with various thiols.

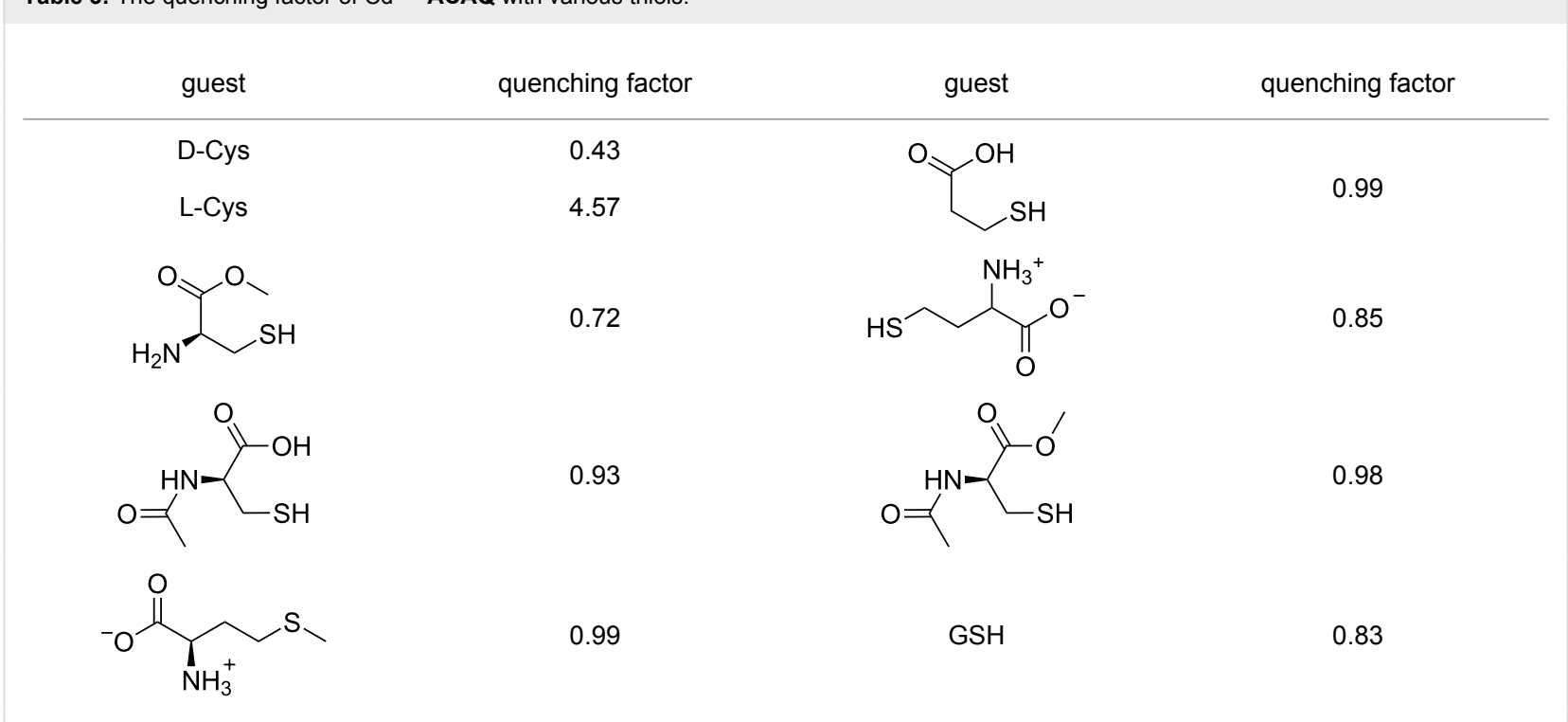




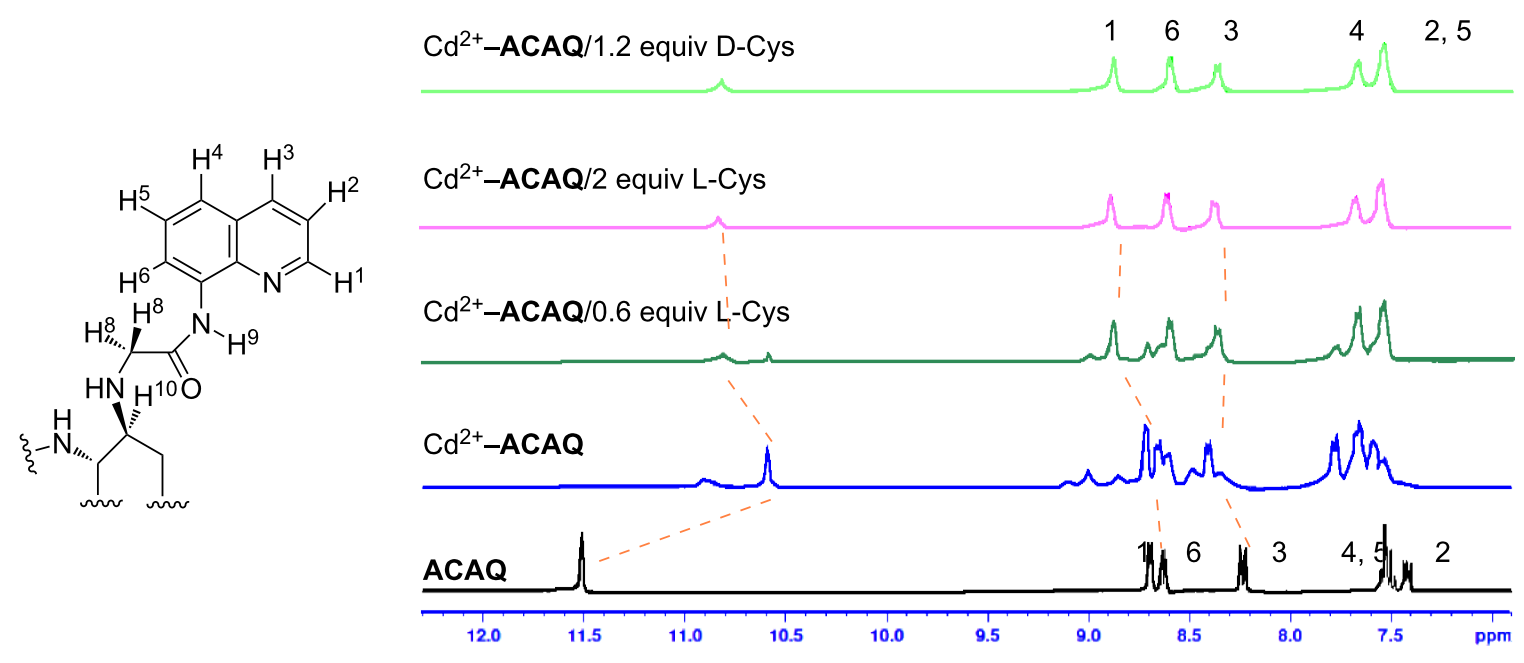

Figure 9: Partial ${ }^{1} \mathrm{H}$ NMR spectra $(400 \mathrm{MHz})$ of ACAQ $(5 \mathrm{mM})$ before and after the addition of $\mathrm{Cd}^{2+}$ and then incremental addition of cysteine in DMSO- $d_{6}$.

quenching ability of the derivative toward the probe was greatly reduced.

To evaluate the binding mode of the $\mathrm{Cd}^{2+}$-ACAQ complex with Cys, detailed ${ }^{1} \mathrm{H}$ NMR titrations were carried out. Upon gradual addition of Cys to the DMSO- $d_{6}$ solution of the ensemble, the amide proton resonating at $\delta 10.60$ experienced a downfield shift to $\delta 10.75$, implying a weakening of the interaction between the carboxamido oxygen and cadmium, presumably due to the ligating effect of Cys on cadmium. While Cys exerts its coordinating influence on cadmium, the coordination of the other nitrogen chelating sites of ACAQ with cadmium is reduced. As a result of the "demetalation" from ACAQ, triggered by the addition of Cys, all protons in the vicinity of these ligating groups underwent resonance shifts to different extents. For instance, as shown in Figure 9, a considerable downfield/<smiles>CC[C@H](N)C(=O)[O-]</smiles>

Figure 10: Proposed binding model of $\mathrm{Cd}^{2+}-\mathbf{A C A Q}$ with cysteine. upfield shift of H1, H2 and H3 was observed. It should be noted that a larger downfield shift of H1 in ACAQ was induced by the addition of D-Cys in comparison with that with L-Cys $(\Delta \delta=$ 0.08 vs 0.05 ). With the support of all the mentioned spectral evidence, the binding model of the probe is proposed in Figure 10.

To rule out the possibility that the observed fluorescence ratiometric change is due to chemical reaction (i.e. chemodosimeter), the reversible binding of Cys and the probe must be established. As shown in Figure 11, the fluorescence spectrum of $\mathrm{Cd}^{2+}-\mathbf{A C A Q}$ can be fully recovered when 10 equivalents of $\mathrm{Hg}^{2+}$, which is a scavenger of Cys, was introduced.

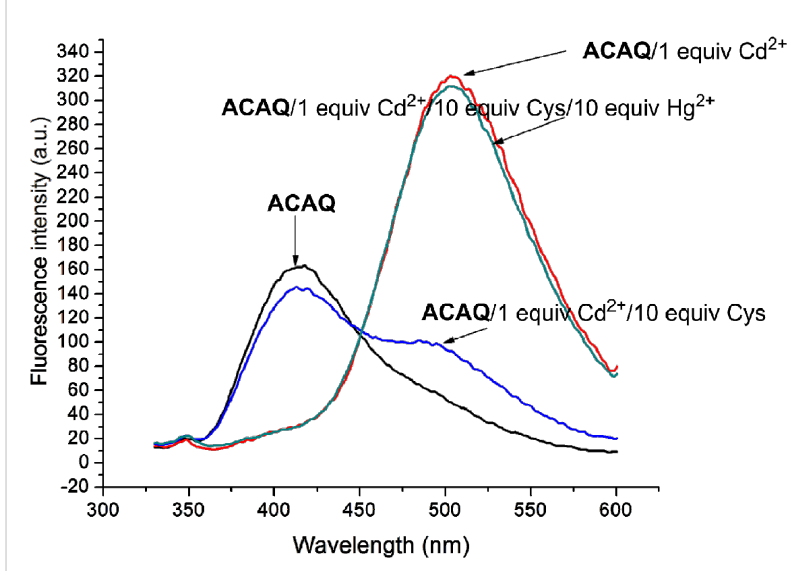

Figure 11: Reversibility study. Emission spectra of $\mathrm{Cd}^{2+}-\mathrm{ACAQ}$ complex $(5 \mu \mathrm{M})$ with 10 equiv L-Cys in buffer solution (10 mM, HEPES, $80 \% \mathrm{ACN}, \mathrm{pH} 7.4)$ at $298 \mathrm{~K}$, then 10 equiv of $\mathrm{Hg}^{2+}$. Excitation wavelength was $315 \mathrm{~nm}$. 


\section{Conclusion}

In summary, a simple, water-soluble, "chemosensing-ensemble" probe for chemo- and enantioselective detection of D-Cys was described. Among all amino acids that were investigated, only Cys and Hcy were responsive to the probe. Significantly, the probe not only demonstrated its outstanding discriminative power on Cys over Hcy and GSH in $99 \%$ aqueous buffered solution, but it also exhibited modest enantioselectivity on Cys for the first time.

\section{Experimental}

Proton NMR spectra were recorded on a Bruker Avance-III 400 spectrometer at $400 \mathrm{MHz}$ in DMSO- $d_{6}$. Fluorescence emission spectra and UV-vis spectra were collected on a PE LS50B and a Cary UV-100 spectrometer, respectively. All inorganic reagents and amino acid derivatives were of analytical reagent grade and were obtained from Aldrich or Sigma. ACAQ was synthesized according to our method [16]. The stock solution of $1.0 \times 10^{-3}$ M ACAQ was obtained by dissolution of the compound in ACN. The stock solutions of $5.0 \times 10^{-3} \mathrm{M}$ amino acids were prepared by dissolution of the material in water. Working solutions were obtained by series dilution with HEPES, pH 7.4 solution.

Association constants (1:1) of $\mathrm{Cd}^{2+}-\mathrm{ACAQ}$ with anions were calculated by nonlinear least-squares curve fitting with the following equation in Origin 7.5:

$\frac{I}{I_{0}}=1+\frac{I_{\lim } / I_{0}-1}{2}\left[1+\frac{\mathrm{C}_{\mathrm{A}}}{\mathrm{C}_{\mathrm{H}}}+\frac{1}{\mathrm{kC}_{\mathrm{H}}}-\sqrt{\left(1+\frac{\mathrm{C}_{\mathrm{A}}}{\mathrm{C}_{\mathrm{H}}}+\frac{1}{\mathrm{kC}_{\mathrm{H}}}\right)^{2}-4 \frac{\mathrm{C}_{\mathrm{A}}}{\mathrm{C}_{\mathrm{H}}}}\right.$,

where $I_{0}$ is the fluorescence intensity of the host without anions, $I_{\text {lim }}$ is the limit of the fluorescence intensity upon addition of excessive anions, $\mathrm{C}_{\mathrm{A}}$ is the concentration of anions added, and $\mathrm{C}_{\mathrm{H}}$ is the concentration of the host molecule. The $I$ was replaced with A, the absorption of UV-vis, when the UV-vis spectra were used.

\section{Acknowledgements}

The financial support of this work by the University Grants Committee of the Hong Kong SAR, China (HKBU 200208) is acknowledged.

\section{References}

1. Hong, R.; Han, G.; Fernández, J. M.; Kim, B.-j.; Forbes, N. S.; Rotello, V. M. J. Am. Chem. Soc. 2006, 128, 1078-1079. doi:10.1021/ja056726i

2. Schulz, J. B.; Lindenau, J.; Seyfried, J.; Dichgans, J. Eur. J. Biochem. 2000, 267, 4904-4911. doi:10.1046/j.1432-1327.2000.01595.x

3. Shahrokhian, S. Anal. Chem. 2001, 73, 5972-5978. doi:10.1021/ac010541m
4. Seshardri, S.; Beiser, A.; Selhub, J.; Jacques, P. F.; Rosenberg, I. H.; D’Agostino, R. B.; Wilson, P. W. B. N. Engl. J. Med. 2002, 346, 476-483. doi:10.1056/NEJMoa011613

5. Nekrassova, O.; Lawrence, N. S.; Compton, R. G. Talanta 2003, 60 , 1085-1095. doi:10.1016/S0039-9140(03)00173-5

6. Chen, X.; Zhou, Y.; Peng, X.; Yoon, J. Chem. Soc. Rev. 2010, 39, 2120-2135. doi:10.1039/b925092a

7. Shiu, H.-Y.; Chong, H.-C.; Leung, Y.-C.; Wong, M.-K.; Che, C.-M. Chem.-Eur. J. 2010, 16, 3308-3313. doi:10.1002/chem.200903121

8. Lin, W.; Yuan, L.; Cao, Z.; Feng, Y.; Long, L. Chem.-Eur. J. 2009, 15, 5096-5103. doi:10.1002/chem.200802751

9. Yi, L.; Li, H.; Sun, L.; Liu, L.; Zhang, C.; Xi, Z. Angew. Chem., Int. Ed. 2009, 48, 4034-4037. doi:10.1002/anie.200805693

10. Chen, X.; Ko, S.-K.; Kim, M. J.; Shin, I.; Yoon, J. Chem. Commun. 2010, 46, 2751-2753. doi:10.1039/b925453f

11. Kwon, H.; Lee, K.; Kim, H.-J. Chem. Commun. 2011, 47, 1773-1775. doi:10.1039/c0cc04092d

12. Rusin, O.; St Luce, N. N.; Agbaria, R. A.; Escobedo, J. O.; Jiang, S.; Warner, I. M.; Dawan, F. B.; Lian, K.; Strongin, R. M. J. Am. Chem. Soc. 2004, 126, 438-439. doi:10.1021/ja036297t

13. Kim, T.-K.; Lee, D.-N.; Kim, H.-J. Tetrahedron Lett. 2008, 49 , 4879-4882. doi:10.1016/j.tetlet.2008.06.003

14. Lee, K.-S.; Kim, T.-K.; Lee, J. H.; Kim, H.-J.; Hong, J.-I. Chem. Commun. 2008, 6173-6175. doi:10.1039/b814581d

15. Li, H.; Fan, J.; Wang, J.; Tian, M.; Du, J.; Sun, S.; Sun, P.; Peng, X. Chem. Commun. 2009, 5904-5906. doi:10.1039/b907511a

16. Hu, M.; Fan, J.; Li, H.; Song, K.; Wang, S.; Cheng, G.; Peng, X. Org. Biomol. Chem. 2011, 9, 980-983. doi:10.1039/c0ob00957a

17. Yuan, L.; Lin, W.; Yang, Y. Chem. Commun. 2011, 47, 6275-6277. doi:10.1039/c1cc11316j

18. Jung, H. S.; Ko, K. C.; Kim, G.-H.; Lee, A.-R.; Na, Y.-C.; Kang, C.; Lee, J. Y.; Kim, J. S. Org. Lett. 2011, 13, 1498-1501. doi:10.1021/ol2001864

19. Lee, J. H.; Lim, C. S.; Tian, Y. S.; Han, J. H.; Cho, B. R. J. Am. Chem. Soc. 2010, 132, 1216-1217. doi:10.1021/ja9090676

20. Piggott, A. M.; Karuso, P. Anal. Chem. 2007, 79, 8769-8773. doi:10.1021/ac071518p

21. Pires, M. M.; Chmielewski, J. Org. Lett. 2008, 10, 837-840. doi:10.1021/ol702769n

22. Ahn, Y.-H.; Lee, J.-S.; Chang, Y.-T. J. Am. Chem. Soc. 2007, 129 , 4510-4511. doi:10.1021/ja068230m

23. Han, B.; Yuan, J.; Wang, E. Anal. Chem. 2009, 81, 5569-5573. doi:10.1021/ac900769h

24. Zhang, M.; Yu, M.; Li, F.; Zhu, M.; Li, M.; Gao, Y.; Li, L.; Liu, Z.; Zhang, J.; Zhang, D.; Yi, T.; Huang, C. J. Am. Chem. Soc. 2007, 129, 10322-10323. doi:10.1021/ja073140i

25. Chow, C.-F.; Chiu, B. K. W.; Lam, M. H. W.; Wong, W.-Y. J. Am. Chem. Soc. 2003, 125, 7802-7803. doi:10.1021/ja034891x

26. Sudeep, P. K.; Joseph, S. T. S.; Thomas, K. G. J. Am. Chem. Soc. 2005, 127, 6516-6517. doi:10.1021/ja051145e

27. Fu, Y.; Li, H.; Hu, W.; Zhu, D. Chem. Commun. 2005, 3189-3191. doi:10.1039/b503772g

28. Li, X.; Qian, S.; He, Q.; Yang, B.; Li, J.; Hu, Y. Org. Biomol. Chem. 2010, 8, 3627-3630. doi:10.1039/c004344c

29. Sreejith, S.; Divya, K. P.; Ajayaghosh, A. Angew. Chem., Int. Ed. 2008, 47, 7883-7887. doi:10.1002/anie.200803194

30. Zhu, B.; Zhang, X.; Li, Y.; Wang, P.; Zhang, H.; Zhuang, X. Chem. Commun. 2010, 46, 5710-5712. doi:10.1039/c0cc00477d

31. Long, L.; Lin, W.; Chen, B.; Gao, W.; Yuan, L. Chem. Commun. 2011, 47, 893-895. doi:10.1039/c0cc03806g 
32. Soutourina, J.; Blanquet, S.; Plateau, P. J. Biol. Chem. 2001, 276, 40864-40872. doi:10.1074/jbc.M102375200

33. Shao, N.; Jin, J.; Wang, H.; Zheng, J.; Yang, R.; Chan, W.; Abliz, Z. J. Am. Chem. Soc. 2010, 132, 725-736. doi:10.1021/ja908215t

34. Shao, N.; Jin, J. Y.; Cheung, S. M.; Yang, R. H.; Chan, W. H.; Mo, T. Angew. Chem., Int. Ed. 2006, 45, 4944-4948. doi:10.1002/anie.200600112

35. Zhou, X.; Lu, Y.; Zhu, J.-F.; Chan, W.-H.; Lee, A. W. M.; Chan, P.-S.; Wong, R. N. S.; Mak, N. K. Tetrahedron 2011, 67, 3412-3419. doi:10.1016/j.tet.2011.03.053

\section{License and Terms}

This is an Open Access article under the terms of the Creative Commons Attribution License

(http://creativecommons.org/licenses/by/2.0), which permits unrestricted use, distribution, and reproduction in any medium, provided the original work is properly cited.

The license is subject to the Beilstein Journal of Organic Chemistry terms and conditions:

(http://www.beilstein-journals.org/bjoc)

The definitive version of this article is the electronic one which can be found at: doi:10.3762/bjoc.7.176 